Article

\title{
Evaluating Consumers' Willingness to Pay for Delay Compensation Services in Intra-City Delivery-A Value Optimization Study Using Choice
}

\author{
Ruixu Pan ${ }^{1}$, Yujie Huang ${ }^{2, *(1)}$ and Xiongwu Xiao ${ }^{3}$ (1) \\ 1 Foisie Business School, Worcester Polytechnic Institute, Worcester, MA 01609, USA; rpan@wpi.edu \\ 2 College of Economics and Trade, Xinjiang Agricultural University, Urumqi 830052, China \\ 3 State Key Laboratory of Information Engineering in Surveying, Mapping, and Remote Sensing, Wuhan \\ University, Wuhan 430079, China; xwxiao@whu.edu.cn \\ * Correspondence: 320192793@xjau.edu.cn
}

Citation: Pan, R.; Huang, Y.; Xiao, X. Evaluating Consumers' Willingness to Pay for Delay Compensation Services in Intra-City Delivery-A Value Optimization Study Using Choice. Information 2021, 12, 127. https://doi.org/10.3390/info12030127

Academic Editor: Hak-Seon Kim

Received: 24 February 2021

Accepted: 15 March 2021

Published: 16 March 2021

Publisher's Note: MDPI stays neutral with regard to jurisdictional claims in published maps and institutional affiliations.

Copyright: (c) 2021 by the authors. Licensee MDPI, Basel, Switzerland. This article is an open access article distributed under the terms and conditions of the Creative Commons Attribution (CC BY) license (https:// creativecommons.org/licenses/by/ $4.0 /)$.

\begin{abstract}
Intra-city delivery has developed rapidly along with the expansion of the logistics industry. Timely delivery is one of the main requirements of consumers and has become a major challenge to delivery service providers. To compensate for the adverse effects of delivery delays, platforms have launched delay compensation services for consumers who order. This study quantitatively evaluated consumer perception of the delay compensation service in intra-city deliveries using a choice experiment. We explored how different attributes of the delay compensation service plan affect consumer preference and their willingness to pay for the services. These service attributes are "delay probability display", "compensation amount", "compensation method", "penalty method for riders", and "one-time order price". Using a multinomial logit model to analyze the questionnaire results, the respondents showed a positive preference for on-time delivery probability display, progressive compensation amount, and cash compensation. The results also show that the respondents opposed the penalty scheme where the riders would bear the compensation costs. Positive preference attributes are conducive to enhancing consumers' willingness to order and pay for the program. Based on our findings and research conclusions, we proposed several recommendations to improve the delay compensation service program.
\end{abstract}

Keywords: light city logistics; intra-city delivery; delay compensations; willingness to order; choice experiment

\section{Introduction}

With rapid developments in mobile Internet, the collaboration of e-commerce, media, and logistics platforms has brought tremendous changes to people's shopping experience [1]. At the same time, Logistics companies have integrated technologies, such as the Internet of Things, cloud computing, and artificial intelligence, to develop new competitive advantages [2]. Given this industry environment, the intra-city delivery, a city-wide short-distance light logistics distribution, has emerged. Under the business model of the intra-city delivery, it can realize the Online to Offline (O2O) model of multiple categories, such as takeaway catering, fresh groceries, medical drugs, and door-to-door services, through Business to Customer (B2C) or Customer to Customer (C2C) businesses, such as online booking, order placement, and offline consumption. Therefore, we define intra-city delivery in this paper: intra-city delivery is an express delivery service carried out by logistics companies for senders and recipients in different areas of the same city.

As the Internet consumer market becomes more segmented, user needs have become more refined. The intra-city delivery can provide consumers with a more efficient and professional service and added convenience in the last mile delivery. In China, the rapid growth of the intra-city delivery market has propelled the creation and growth of numerous 
urban logistics service companies, such as Fengniao Distribution, Xindada, and Meituan Distribution. By the third quarter of 2019, the transaction scale of the intra-city distribution market in China reached 79.52 billion yuan with 470 million users [3]. Therefore, the intracity delivery has become an important segment of light city logistics with huge market scale and development potential.

From the perspective of practice, delivery time and delivery delay are one of the most important problems affecting consumer experience in light city logistics industry such as the intra-city delivery. In delivery services, merchants would need to agree with the consumers on the estimated delivery time and ensure delivery timeliness. If the products are not delivered on time, consumer satisfaction with services is significantly reduced [4]. Due to the characteristics of the products, the demand for timeliness in intra-city distribution is considerably greater than regular express logistics [5]. Research has shown that among the user experience factors in intra-city delivery, $52.4 \%$ of the respondents consider the immediateness of delivery as their primary concern [3]. Similarly, according to survey statistics, one in five consumers check their phones to track their food delivery's real-time location, at least once. This behavior reflects how consumers are extremely sensitive to the timeliness of delivery [6]. Delays in delivery services would negatively impact users' waiting emotions, causing them to experience pain points.

To meet the demand for prompt and timely delivery, platforms may need to increase the number of distribution personnel, which would result in substantially higher distribution costs [7]. Efficient supply chain management includes high-quality customer service and efforts to reduce circulation costs [8], and cost control is a key point in platform operations. In many instances, cost constraints may be the reason for intra-city delivery delays (i.e., due to cost constraints, the delivery staff is insufficient, and the single delivery time exceeds the scheduled period), causing a decline in consumer satisfaction and willingness to repurchase. Therefore, in the case of reducing the cost of distribution, it is particularly important to improve the service quality of distribution.

To reduce consumer dissatisfaction, reduce the cost of distribution, and compensate for the negative effects of delays, intra-city distribution platforms often launch delay compensation services for consumers to choose from. When delays occur, the platform will compensate a certain amount according to the corresponding plan to counteract consumer dissatisfaction and indicate corporate responsibility. For example, the three companies that occupy the top of the intra-city delivery, Fengniao Distribution, Xindada, and Meituan Distribution, have launched various delay compensation services Zhunshida, Zhunshibao, and Weichangzhun. The delay compensation service is a good response to counteract the anxiety caused by waiting, especially waiting without a clear duration [9]. Research has shown that as the total value consumers receive from services goes up, the shorter the consumers perceive the waiting time [6]. This can effectively reduce their anxiety and helplessness. Providing delay compensation has become an effective approach to minimize perceived waiting time [10] and reduce consumer anxiety. However, we still do not know the extent of consumers' preference for the attribute in delay compensation service for intra-city delivery, which will affect consumers' willingness to pay for delay compensation service.

Compared with other methods, choice experiment (CE) can accurately measure consumers' preferences for important attributes of a product and provide more information about the attribute preferences when consumers make product choices [11], Therefore, CE is suitable for this study to detect consumers' preferences for different attributes of delay compensation service for intra-city delivery as well as consider the influence of different social demographic factors on the attribute preferences of consumers. To the best of our knowledge, this is the first study to research the preferences for delay compensation service. Using choice experiment to analyze consumer behavior, this study focuses on the delay compensation service plan in intra-city delivery. A questionnaire survey was conducted to obtain first-hand data on users' preferences for attributes of delay compensation services. A multinomial logit model was used to calculate user preferences and willingness to pay 
for different service attributes and find the optimal attribute combination. We also explored the correlation between the users' socio-economic profile and five service attributes: delay probability display (none, 99\% arrive on time, 1\% delay), compensation amount (fixed amount, progressive amount), compensation method (cash, voucher), penalty method for riders (none, rider bears the compensation, reduce rider's credit score), and the one-time order price (0.3 yuan, 0.6 yuan, 0.9 yuan, 1.2 yuan). Based on the results, suggestions for platforms to improve delay compensation service for intra-city delivery are proposed.

\section{Literature Review and Hypotheses Development}

\subsection{Service Innovation of Intra-City Distribution}

Previous studies have found that price is an economic factor that determines people's loyalty to light logistics services [12]. However, as the light industry logistics service has gradually entered the mature stage, that is, the market saturation and enterprise scale are becoming more and more perfect, it is difficult for enterprises to compete for new consumers and distinguish themselves from competitors through a simple price war. Therefore, from price competition to user experience competition, optimizing user experience and improving subjective feelings have become important mechanisms to improve a competitive advantage [6]. Intra-city distribution can increase the complexity of services or enhance the perceived value of services to improve consumer satisfaction, thus creating competitive advantages [13]. In a word, increasing the service experience of consumers is an important way for light logistics enterprises to compete in the future.

User experience is a dynamic process [14], which is affected not only in the actual use or consumption of a product but also by the entire product-service [15]. Therefore, many scholars focus on the optimization of consumer experience of intra-city distribution, and scholars have studied experience of intra-city distribution from different perspectives, including the competitive advantage of service experience [16], the influence of service experience on repurchase intention [17], the formation of consumer satisfaction [18], the personalized logistics service function [19,20], and the differentiated service advantage [21]. Specifically, related [16] research shows that the service quality of intra-city delivery is the biggest competitive advantage in the industry. Its quality and effect determine consumer satisfaction, directly impacting users' willingness to repurchase on platforms [17]. These factors can also affect users' decision-making processes, such as cognition and evaluation of platforms, thereby increasing user satisfaction and forming a new ordering behavior [18]. Functional modules, review systems, and personalized logistics service functions [19] have become the main technical carriers to improve service quality. These service innovations can improve competitiveness and meet more individualized use needs [20] that give logistics service companies differentiated advantages [21].

It is necessary to improve the service experience of consumers through the service innovation or technology of logistics. For example, in conjunction with planned behavior, a related study examines the phenomenon of food delivery services from the perspective of mobile app users, as well as the primary motivations that lead consumers to use and recommend these technology-based services. The researchers found that perceived control is only important for older customers, who need to perceive that they control the apps before they will recommend them to other customers [22]. At the same time, logistics service innovation involves changing existing service processes and products using new technologies and knowledge in order to improve the quality of existing services, expand service contents, or increase the added value of logistics services [23,24]. Therefore, delay compensation service is not only the innovation of logistics service but also an effective tool to improve consumers' perceived control level of logistics delivery time.

Delay compensation service belongs to the value-added part of the distribution system [25]. Delay compensation service, similar to other parts of logistics service, will affect users' perception of service value [26], and delay compensation service will also be an important manifestation of logistics service quality. A compensation service with reasonable configuration can help improve users' perceived usefulness or ease of use for the 
service, which is important in enhancing the level of user service exposure [5]. Conversely, if the design of a compensation service is unreasonable, and the perceived usefulness is poor, it will not encourage users to order, and the service will be useless. Moreover, unreasonable compensation service settings may be counterproductive and even increase user dissatisfaction. Previous studies have analyzed the importance of logistics service innovation [25,26]. However, previous studies have not analyzed how to optimize and design logistics services, especially logistics compensation services, from the perspective of consumer experience. Therefore, although the delay compensation service can affect the consumer's value perception of the service, there is no research on the optimization of logistics compensation services.

Studies have shown that dissatisfaction, generated by long waiting times, can easily give service providers a negative reputation through word-of-mouth [27]. However, much of the research on distribution platforms focuses mainly on price, category, convenience, or customer service [28]. The delay compensation service has often been excluded. In particular, the analysis of major attributes in delayed service (i.e., delay probability display, compensation amount, compensation method, penalty method for riders, and one-time order price) is unknown. So, this article addresses this oversight and focuses on evaluating the effects of delay compensation service plans in the inter-city logistics service industry.

\subsection{Delay Compensation Service for Intra-City Delivery}

Product delivery time is one of the main factors that affect consumers' repeated purchase decision and satisfaction [29]. The delayed delivery of online shopping goods will negatively affect consumers' satisfaction with e-commerce enterprises, and in the process of service recovery, material compensation can increase consumers' satisfaction and prompt consumers to change their subsequent behavior [30]. So, as a service innovation, the core of the delay compensation service is to provide a remedial plan to reduce the negative impact caused by service failures [2] in order to maintain consumer loyalty and trust. Studies have shown that the form of refund or compensation can reduce consumer complaints to a certain extent [31]. The service remediation paradox believes that if a certain amount of compensation is given for service failures (e.g., delivery overtime) and the issues get satisfactorily resolved afterward, consumers tend to have better service experiences or higher satisfaction [32]. However, how the delay compensation service can satisfy consumers and generate a certain service experience has not been fully studied in the academic research field.

Delay compensation service is an active type of compensation. Compared with the passive form, this system can create more positive emotions and higher user stickiness [33]. However, $40 \%$ to $60 \%$ of users are not satisfied with most compensation services, which is often due to a faulty or ineffective compensation process [34]. Therefore, designing a fair and reasonable delay compensation service plan with strong compensation effectiveness can reduce complaints and increase consumer satisfaction and trust in platforms. It's also a great way to create a user experience [6].

Different from the relative lag of academic research, the logistics service industry has formed a number of attributes of delayed compensation service in a large number of practices as well as designed different schemes of delayed compensation. For the delay compensation service plan, each platform may have different attributes and attribute levels. For example, in terms of the type of compensation, Zhunshibao of Meituan pays a cash balance, while Zhunshida of Fengniao pays red envelopes. In terms of compensation value, Meituan's compensation is based on delay time and increases in a stepwise manner, while Xindada pays a fixed amount. Can these different attributes and levels better alleviate users' dissatisfaction with delays, and can they attract users to order delay compensation services? The effectiveness and usefulness of these compensation systems to increase user satisfaction and consumer loyalty are integral in the future developments and improvements to the intra-city logistical service industry. Therefore, we need to study these attributes for the 
first time and use CE to determine the impact of different attributes and levels in these services on users' willingness to order.

\subsection{User's Willingness to Order}

As a value-added service, delay compensation service requires a certain degree of subscription by users to take effect. Therefore, compensation services need to stimulate consumers' willingness to order in order to form a corresponding effective transaction. Related studies have shown that in the context of e-commerce, some subtle transaction factors, such as the payment method for delivering cash, affect consumers' preference for e-commerce platforms. This also illustrates the importance of optimizing the elements of the trading scheme in trading [35]. Therefore, the influencing factors of purchase intention and satisfaction of intra-city delivery service are studied and analyzed. For example, Chen [36] confirmed that the user-friendliness of platforms, the convenience of operation, the timeliness of information, and the reliability of services are the main factors improving users' perceived value and satisfaction. Gao [37] studied the impact of platform usability, service response, and information content on user perception using the $\mathrm{O} 2 \mathrm{O}$ model based on the American Customer Satisfaction Index (ACSI) theory. Zeng [28] proposed a fuzzy evaluation model of customer satisfaction in $\mathrm{O} 2 \mathrm{O}$ delivery and found that there are three influencing factors in consumer satisfaction: food factor, price factor, and service factor. Jiang [38] found that using a fast and efficient website in order distribution can improve user satisfaction and increase their willingness to repeat consumption. He [39] concluded that safety and speed are critical factors in the online distribution industry and found that logistics and distribution services are the primary bottlenecks. While these studies were able to analyze user satisfaction and willingness to order in intra-city delivery in terms of information reliability, usability, convenience [36], service factors [37], food factor, price factor, and service factor [28], and efficiency [38], the willingness to order delay compensation services have been overlooked, particularly in relation to how they affect the perceived value of the order itself.

A major goal of service design is to increase the consumer's willingness to pay, which is inextricably linked with the value or attitude that consumers perceive for the service [40] and is mainly associated with consumer trust. In other words, trust is an important bridge to improve consumers' perception of service value. Trust is a safe, reliable, and effective positive expectation [41]. Relevant research studies show that the determinants of network trust include website characteristics, customer characteristics and other factors. Results include behavioral intention, stakeholder satisfaction, loyalty, traffic, price, revenue, profitability, etc. [42]. At the same time, six factors can improve users' trust in e-commerce, including payment choice, punctuality, after-sales service quality, and so on [43]. In other words, trust is the bridge between the service plan and the purchase intention, and in the process of forming this expectation, consumers require experience or external information (e.g., content information contained in the delay compensation service) to build trust in an object. However, uncertainties and perceptions of risks can have significant impact on consumer trust [44]. Strategies, such as stipulating truthful estimates for delays and providing clear compensation amounts, can be used to reduce uncertainties in delay compensation services. The elimination of uncertainty may be another bridge to improve consumers' perception of service value.

Doubts regarding technical information can have adverse effects on consumer trust [45], particularly when they are not sure whether the compensation service would actually bring benefits from them or if it is just a sales approach that encourages them to order again on those platforms. From the importance of service design, a good service design can substantially minimize doubt and ambiguity, improve client confidence, and increase consumers' willingness to order. By optimizing the service plan, the usability and reliability of the service can significantly improve, and the likelihood that consumers order the service can increase. Therefore, we believe that a good delay compensation service can increase 
consumers' willingness to order and pay for the service through the bridge of increasing trust and reducing worry.

To sum up, it can be seen from previous studies that different scholars have analyzed the influencing factors of consumer satisfaction and purchase intention in intra-city distribution from their own perspectives, such as information reliability, ease of use, service factors, efficiency, etc. However, the literature has not explored the influencing factors of the ordering intention of the delay compensation service and analyzed how to improve the price of consumers for the delay compensation service. In practice, customers' behavioral intentions depend on their perceptions of the service quality [46]. So, we believe that by optimizing the delay compensation service scheme, the ease of use and reliability of the delay compensation service itself can be improved, such as a clearer display of compensation amount and more detailed presentation of compensation probability, so that consumers can better understand and are more inclined to order the service. At the same time, a better delay compensation service can also increase the potential perceived value of the order. Therefore, we think compared with the general scheme and other schemes, the optimal scheme of delay compensation service of intra-city delivery can increase consumers' ordering willingness. We propose the following hypotheses in this paper:

Hypothesis 1. The optimal delay compensation service scheme can significantly increase consumers' ordering and payment price for delay compensation service.

This optimal structure contains the optimal level of five attributes, namely delay probability display, compensation amount, compensation method, penalty method, and one-time order price. The five attributes will be discussed in detail in the next section. Considering that consumers with different socio-demographics will have different perceptions of attributes $[47,48]$, especially factors such as age, gender, income level, and education background, this paper also takes demographic characteristics as a factor affecting the deferred compensation scheme and puts forward the following hypotheses:

Hypothesis 2. Consumers' socio-demographic and attribute level will have an interactive effect on consumers' ordering and payment price for delay compensation service.

To explore more deeply how the delay compensation service plan affects consumers' willingness to order (Hypotheses 1 and 2), we evaluated five attributes and 14 levels of consumer preference schemes using choice experiment analysis. This study investigates how an optimized plan can affect consumers' willingness to order, particularly the interaction between different consumer demographics and service plans.

\section{Methodology}

According to the consumer theory proposed by Lancaster [49], the utility of consumers comes from various attributes of a commodity, rather than the commodity itself. In other words, in the delay compensation service, consumers' value perception does not come from the compensation service but from the different attributes of the compensation service. Therefore, this paper needs to use a micro-approach of consumer research to obtain and analyze the differences in consumers' perceived value for different attributes of compensation services. We chose the choice experiment method to analyze consumers' perceived value of attributes.

In recent years, choice experiments have been used in various fields, mostly in research on consumers' preferences of various attributes [50,51]. This is because choice experiments can effectively reduce research errors by selecting combinations of different attributes and more accurately reflect consumer preference and willingness to pay for different attributes [52]. Several studies have focused on the attitudes or preferences of consumers for the compensation services of delivery serving [25,26]. However, there is no research that combines this area with the choice experiment to study the value perception of consumers for the attribute of compensation service. Therefore, in the current study, we adopted a 
choice experiment approach to detect consumer preferences for compensation services in intra-city delivery at the attribute level, and choice experiment can further measure the marginal willingness to pay for the compensation services. In the following sections, we will introduce three aspects in detail: attribute selection of delay compensation service, sample collection required for experiment, and model selection.

\subsection{Attribute Selection}

In choice experiment, the selection of commodity attributes determines the effectiveness and the accuracy of the results [53]. Too many attributes may cause information overload, affecting consumers' perception and judgment of attributes, while too few may lead to missing or insufficient variables, resulting in estimation bias [52]. Whether the selected attribute is reasonable depends mainly on the policy meaning of the attribute or its importance to consumer preferences. In this study, five attributes in delay compensation service were analyzed: delay probability display, compensation amount, compensation method, penalty method for riders, and one-time order price. Since study on the compensation service in intra-city delivery is still in its infancy, except for delay probability display, we selected other attributes in this study according to the real compensation service in the real delivery markets.

While delay probability display is widely used in traffic navigation, this parameter is not common in intra-city delivery services. Through personal communications with a department manager of an intra-city delivery company, we learned that the current delay probability for intra-city delivery in the market is generally less than $1 \%$. For this study, we designed three levels for the delay probability display attribute: (1) none, (2) 99\% arriving on time, and (3) $1 \%$ delay. The first level is none, because in practice, many merchants do not present the delay probability of order service; it is also used as a benchmark group to compare whether consumers' ordering intention will change when the probability of delay is presented. In addition, we consider framing effect [54], that is, people's views of gains and losses are based entirely on their perceived reference points, and they make decisions differently depending on the reference points. So even though the $99 \%$ on-time rate and $1 \%$ delay rate are the same, consumers will have different reference points and further form different ordering intentions.

For the compensation value, there are two main forms in the realistic market: fixed amount and progressive amount (the amount increases as the delay time increases). The dynamically increasing value estimation usually has a maximum limit. In this study, two levels for the compensation amount parameter were used: (1) fixed amount and (2) progressive amount (up to $70 \%$ of the product). We hope to improve consumers' perception of compensation value without changing the cost of compensation by finding out the forms of compensation value that consumers prefer more. For the compensation method parameter, the two common types of compensation were used as the attribute levels: (1) cash refund and (2) gift vouchers. Since different in-city delivery service providers in China have adopted different forms of compensation, we hope to explore the influence of these two forms of compensation on consumers' ordering intention through scientific methods so as to change the compensation forms of service providers in a directional way. For the penalty-method parameter, three levels were used based on existing plans and a review of related studies. These are (1) no penalty, (2) the rider bears the compensation, and (3) the rider's credit score is penalized. This point is based on a large number of order complaints to explore whether consumers will be willing to punish the deliverers who cause delivery delays, so as to better enable the service providers to manage the relationship between consumers and deliverers and even reduce consumer complaints by punishing the delayed deliverers. For the fifth attribute, the current average price for delay compensation service is about 0.3 yuan/time. In this study, we used four attribute levels, raising the base price by $100 \%, 200 \%$, and $300 \%$. The attribute levels for the one-time order price parameter are: (1) 0.3 , (2) 0.6 , (3) 0.9 , and (4) 1.2 . Table 1 provides a summary detailing the attributes and attribute levels used in this study. 
Table 1. Attributes and levels of compensation services.

\begin{tabular}{|c|c|c|}
\hline Attribute & Number of Attribute Levels & Levels \\
\hline Delay Probability Display & 3 & $\begin{array}{c}\text { None } \\
99 \% \text { Arrive On-Time } \\
\text { 1\% Delay }\end{array}$ \\
\hline Compensation Amount & 2 & $\begin{array}{c}\text { Fixed Amount } \\
\text { Progressive Amount (Up to } \\
70 \% \text { of The Product) }\end{array}$ \\
\hline Compensation Method & 2 & $\begin{array}{c}\text { Cash } \\
\text { Vouchers }\end{array}$ \\
\hline Penalty Method for Riders & 3 & $\begin{array}{l}\text { None Penalty } \\
\text { Rider Bears Compensation } \\
\text { Reduce Rider's Credit Score }\end{array}$ \\
\hline One-Time Order Price & 4 & $\begin{array}{l}0.3 \\
0.6 \\
0.9 \\
1.2\end{array}$ \\
\hline
\end{tabular}

Given the number of attributes and attribute levels, we generated $3 \times 2 \times 2 \times 3 \times 4=144$ full-factor choice sets. However, considering the consumers' information-carrying capacity and logistical considerations for the research, investigating all 144 choice sets would be extremely difficult. Therefore, we adopted the D-optimal partial factorial design to reduce the asymptotic standard error between attributes while maintaining the method's effectiveness (D-efficiency) [55]. Thirty-six choice sets were generated through Negene1.0, with a D-efficiency of $93.80 \%$ and D-error of 0.09 , which met the research needs. Each choice set contained two generated scenarios (Scenario 1 and Scenario 2) and a third option where no delay compensation service is selected (see Table 2). Finally, the 36 choice sets were divided into six questionnaires. Each questionnaire contained two parts: basic consumer demographics and six random choice sets.

Table 2. A sample of choice sets.

\begin{tabular}{|c|c|c|c|}
\hline & Scenario 1 & Scenario 2 & Scenario 3 \\
\hline Delay Possibility Display & 1\% Delay & 99\% Arrive On-Time & \multirow{5}{*}{ None } \\
\hline Compensation Amount & Fix Amount & $\begin{array}{l}\text { Progressive Amount (Up } \\
\text { to } 70 \% \text { of the Product) }\end{array}$ & \\
\hline Compensation Method & Cash & Vouchers & \\
\hline Penalty Method for Riders & None & $\begin{array}{l}\text { Rider Bears } \\
\text { Compensation }\end{array}$ & \\
\hline One-Time Order Price & 0.9 Yuan/Time & 1.2 Yuan/Time & \\
\hline What is your choice & $\bigcirc$ & 0 & $\bigcirc$ \\
\hline
\end{tabular}

\subsection{Data Collection}

Research [56] shows no statistical difference between online questionnaires and face-toface interviews. Therefore, online questionnaires were used for convenience and efficiency. The six questionnaires were distributed evenly through the Credamo platform between 5 and 10 October 2020. Credamo focuses on providing an information-based service platform for scientific research institutions to collect large-scale survey data, and Credamo has been used as a source of data acquisition for a number of authoritative journal articles $[57,58]$. We mainly gathered a wide range of sample groups through the Credamo platform, put them into different groups according to the idea of random grouping, and finally answered relevant contents according to the process of experimental design to form sample data. A 
filter question was set to target respondents who had previously used delay compensation services. Finally, 457 questionnaires were collected, and using screening questions to filter the respondents, 420 were considered valid. The questionnaire response rate reached $91.9 \%$.

The respondents' demographic profile is summarized in Table 3. Among the 420 interviewees, $54.52 \%$ were female, and most were below 35 years old. The 25-34 age group comprised the vast majority of respondents, and only one was over 55 years old. The age distribution of the respondents in the survey is in line with the frequency and proficiency of mobile phone users on the national scale. It is also in line with China's in-city delivery service subscription main body being young people. In terms of educational background, 404 interviewees had an associate degree or higher (96.19\%). For income levels, those with monthly incomes of "4000-5999 yuan", "6000-7999 yuan", and "8000-9999 yuan", which accounted for $29.52 \%, 22.38 \%$, and $20.00 \%$ of the respondent population, respectively. In terms of frequency of use, the average amount the respondents use intra-city delivery services was 3.38 .

Table 3. Socio-demographics and economic characteristics of samples.

\begin{tabular}{|c|c|c|c|}
\hline & Variables & Frequency $(N=420)$ & Percentage \\
\hline \multirow[b]{2}{*}{ Gender } & Male & 191 & $45.48 \%$ \\
\hline & Female & 229 & $54.52 \%$ \\
\hline \multirow{6}{*}{ Age } & $\leq 24$ & 56 & $13.33 \%$ \\
\hline & $2 \overline{5}-34$ & 317 & $75.48 \%$ \\
\hline & $35-44$ & 38 & $9.05 \%$ \\
\hline & $45-54$ & 8 & $1.90 \%$ \\
\hline & $55-64$ & 1 & $0.24 \%$ \\
\hline & $\geq 65$ & 0 & 0 \\
\hline \multirow{3}{*}{ Education Level } & High School and Below & 16 & $3.81 \%$ \\
\hline & Associate or Bachelor Degree & 383 & $91.19 \%$ \\
\hline & Master Degree and Above & 21 & $5.00 \%$ \\
\hline \multirow{7}{*}{ Monthly Income } & $<2000$ Yuan & 18 & $4.29 \%$ \\
\hline & 2000-3999 Yuan & 39 & $9.29 \%$ \\
\hline & 4000-5999 Yuan & 94 & $22.38 \%$ \\
\hline & 6000-7999 Yuan & 124 & $29.52 \%$ \\
\hline & 8000-9999 Yuan & 84 & $20.00 \%$ \\
\hline & 10,000-14,999 Yuan & 52 & $12.38 \%$ \\
\hline & $\geq 15,000$ Yuan & 9 & $2.14 \%$ \\
\hline
\end{tabular}

\subsection{Model Selection}

According to the consumer theory [49], the utility function of consumer $\mathrm{n}$ from compensation scenario I can be expressed as:

$$
\mathrm{U}_{n i}=V_{n i}\left(\beta_{n}\right)+\varepsilon_{n i}=\delta(\operatorname{ASC})+\alpha_{n}\left(\mathrm{X}_{i}\right)+\gamma_{n}\left(-P_{i}\right)+\varepsilon_{n i}
$$

where Uni is the indirect utility of scenario I; $V n i$ is the observable utility of the scenario; $\varepsilon$ ni is the random error term, which is the unobservable utility; $X i$ is the attribute of scenario I; and $P i$ is the price of scenario I. ASC is Alternative Specific Constant, such that when the consumer chooses neither scenario 1 nor 2, ASC is assigned a value of 1 ; if the consumer chooses either option 1 or 2 , the ASC value is $0 . \beta n=(\delta, \alpha n, \gamma n)$ is the coefficient of each variable, reflecting the weight of consumers on the utility of scenario 3 , attributes, and price attributes. $f(\varepsilon n i)$ is the distribution hypothesis for $\varepsilon n i$. When $f(\varepsilon n i)$ obeys the 
Gumbel distribution, the probability that consumer $n$ chooses scenario I in scenario J can be expressed as:

$$
P_{n i}=\operatorname{Prob}\left(V_{n i}+\varepsilon_{n i}>V_{n j}+\varepsilon_{n j}, \forall_{j} \neq i\right)=\frac{e^{V_{n i}\left(\beta_{n)}\right.}}{\sum e^{V_{n j}\left(\beta_{n n}\right)}}=\int\left(\frac{e^{V_{n i}(\beta)}}{\sum e^{V_{n j}(\beta)}}\right) f(\beta) d(\beta)
$$

where $\beta$ is the parameter vector; $\left.\int \beta \mid \theta\right)$ is the probability density function of $\beta$; and $\theta$ is the parameter describing the distribution.

$$
\mathrm{WTP}_{n}=-\frac{\beta_{\mathrm{nx}}}{\beta_{\mathrm{np}}}
$$

The willingness to pay (WTP) by consumer $\mathrm{n}$ for attribute $\mathrm{X}$ is expressed in Equation (3). WTP is the ratio of different attributes and prices to the marginal utility for consumer $n$.

\section{Experiment Results}

\subsection{Main Effects Model Estimation Results}

We tested and compared the Multinomial Logit (MNL) and Random Parameter Logit (RPL) models. Based on the principle of Log Likelihood maximization and Akaike Information Criterion (AIC)/Bayesian Information Criterion (BIC) minimization, we compared the values of the two models. The multinomial logit model and random parameter logit model have good fitting results, but the MNL model had a higher log-likelihood value and smaller AIC and BIC. This suggests that the MNL model is more suitable for this study; thus, it is used in the analysis and discussion for the rest of this article. Table 4 shows the estimation results for the MNL model using Stata15.0.

\begin{tabular}{|c|c|c|}
\hline Variables & $\begin{array}{c}\text { Mean Coefficient } \\
\text { of Main Effect } \\
\text { Model (Standard } \\
\text { Deviation Coefficient) }\end{array}$ & $\begin{array}{c}\text { Mean Coefficient of } \\
\text { Interaction Effect } \\
\text { Model (Standard } \\
\text { Deviation Coefficient) }\end{array}$ \\
\hline Price & $\begin{array}{c}-0.655^{* * *} \\
(-7.32) \\
\end{array}$ & $\begin{array}{c}-0.671^{* * *} \\
(-7.38) \\
\end{array}$ \\
\hline \multicolumn{3}{|l|}{$\begin{array}{l}\text { Delay Possibility Display } \\
\text { (Benchmark: None) }\end{array}$} \\
\hline 99\% Arrive On-Time & $\begin{array}{l}0.320 * * * \\
(-5.06)\end{array}$ & $\begin{array}{l}1.485^{* * *} \\
(-2.74)\end{array}$ \\
\hline 1\% Delay & $\begin{array}{c}0.089 \\
(-1.42) \\
\end{array}$ & $\begin{array}{c}0.657 \\
(-1.19)\end{array}$ \\
\hline \multicolumn{3}{|l|}{$\begin{array}{l}\text { Compensation Amount } \\
\text { (Benchmark: Fixed Amount) }\end{array}$} \\
\hline Progressive Amount & $\begin{array}{l}0.262^{* * *} \\
(-5.83)\end{array}$ & $\begin{array}{l}-0.712 * \\
(-1.77)\end{array}$ \\
\hline \multicolumn{3}{|l|}{$\begin{array}{l}\text { Compensation Method } \\
\text { (Benchmark: Cash) }\end{array}$} \\
\hline Vouchers & $\begin{array}{c}-0.571^{* * *} \\
(-12.76)\end{array}$ & $\begin{array}{l}-0.822 * * \\
(-2.04)\end{array}$ \\
\hline \multicolumn{3}{|l|}{$\begin{array}{l}\text { Penalty Method for Riders } \\
\text { (Benchmark: None) }\end{array}$} \\
\hline Rider Bears Compensation & $\begin{array}{l}-0.129 * * \\
(-2.07)\end{array}$ & $\begin{array}{l}1.027 * \\
(-1.82)\end{array}$ \\
\hline Reduce Rider's Credit Score & $\begin{array}{l}-0.046 \\
(-0.74)\end{array}$ & $\begin{array}{c}0.19 \\
(-0.34)\end{array}$ \\
\hline
\end{tabular}

Table 4. Results of the Multinomial Logit MNL model. 
Table 4. Cont.

\begin{tabular}{|c|c|c|}
\hline Variables & $\begin{array}{c}\text { Mean Coefficient } \\
\text { of Main Effect } \\
\text { Model (Standard } \\
\text { Deviation Coefficient) }\end{array}$ & $\begin{array}{l}\text { Mean Coefficient of } \\
\text { Interaction Effect } \\
\text { Model (Standard } \\
\text { Deviation Coefficient) }\end{array}$ \\
\hline ASC & $\begin{array}{l}-2.183^{* * *} \\
(-19.12)\end{array}$ & $\begin{array}{c}-2.879 * * * \\
(-3.68)\end{array}$ \\
\hline Income $\times 99 \%$ Arrive On-Time & & $\begin{array}{l}-0.032 \\
(-0.64)\end{array}$ \\
\hline Income $\times 1 \%$ Delay & & $\begin{array}{c}0.037 \\
(-0.73)\end{array}$ \\
\hline Income $\times$ Progressive Amount & & $\begin{array}{c}0.001 \\
(-0.03)\end{array}$ \\
\hline Income $\times$ Vouchers & & $\begin{array}{l}-0.005 \\
(-0.13)\end{array}$ \\
\hline Income $\times$ Rider Bears Compensation & & $\begin{array}{l}-0.04 \\
(-0.81)\end{array}$ \\
\hline $\begin{array}{c}\text { Income } \times \text { Reduce Rider's Credit } \\
\text { Score }\end{array}$ & & $\begin{array}{l}-0.033 \\
(-0.65)\end{array}$ \\
\hline Income $\times$ ASC & & $\begin{array}{l}-0.091 \\
(-1.22)\end{array}$ \\
\hline Gender $\times 99 \%$ Arrive On-Time & & $\begin{array}{l}-0.282 * * \\
(-2.24)\end{array}$ \\
\hline Gender $\times 1 \%$ Delay & & $\begin{array}{c}0.029 \\
(-0.23)\end{array}$ \\
\hline Gender $\times$ Progressive Amount & & $\begin{array}{c}0.12 \\
(-1.31)\end{array}$ \\
\hline Gender $\times$ Vouchers & & $\begin{array}{c}0.012 \\
(-0.13)\end{array}$ \\
\hline Gender $\times$ Rider Bears Compensation & & $\begin{array}{l}-0.023 \\
(-0.18)\end{array}$ \\
\hline $\begin{array}{c}\text { Gender } \times \text { Reduce Rider's Credit } \\
\text { Score }\end{array}$ & & $\begin{array}{l}-0.07 \\
(-0.55) \\
\end{array}$ \\
\hline Gender $\times$ ASC & & $\begin{array}{l}0.012 \\
-0.07\end{array}$ \\
\hline $\begin{array}{l}\text { Education Level } \times 99 \% \text { Arrive } \\
\text { On-time }\end{array}$ & & $\begin{array}{l}-0.154 \\
(-0.71)\end{array}$ \\
\hline Education Level $\times 1 \%$ Delay & & $\begin{array}{l}-0.312 \\
(-1.37) \\
\end{array}$ \\
\hline $\begin{array}{c}\text { Education Level } \times \text { Progressive } \\
\text { Amount }\end{array}$ & & $\begin{array}{l}0.410^{* *} \\
(-2.5)\end{array}$ \\
\hline Education Level $\times$ Vouchers & & $\begin{array}{l}-0.004 \\
(-0.02)\end{array}$ \\
\hline $\begin{array}{l}\text { Education Level } \times \text { Rider Bears } \\
\text { Compensation }\end{array}$ & & $\begin{array}{l}-0.449 * \\
(-1.93)\end{array}$ \\
\hline $\begin{array}{c}\text { Education Level } \times \text { Reduce Rider's } \\
\text { Credit Score }\end{array}$ & & $\begin{array}{l}-0.069 \\
(-0.31)\end{array}$ \\
\hline Education Level $\times$ ASC & & $\begin{array}{l}1.017^{* * *} \\
(-3.13)\end{array}$ \\
\hline Age $\times 99 \%$ Arrive On-Time & & $\begin{array}{c}-0.243^{* *} \\
(-2.09)\end{array}$ \\
\hline
\end{tabular}


Table 4. Cont.

\begin{tabular}{|c|c|c|}
\hline Variables & $\begin{array}{c}\text { Mean Coefficient } \\
\text { of Main Effect } \\
\text { Model (Standard } \\
\text { Deviation Coefficient) }\end{array}$ & $\begin{array}{c}\text { Mean Coefficient of } \\
\text { Interaction Effect } \\
\text { Model (Standard } \\
\text { Deviation Coefficient) }\end{array}$ \\
\hline Age $\times 1 \%$ Delay & & $\begin{array}{l}-0.112 \\
(-0.96)\end{array}$ \\
\hline Age $\times$ Progressive Amount & & $\begin{array}{l}-0.049 \\
(-0.57)\end{array}$ \\
\hline Age $\times$ Vouchers & & $\begin{array}{c}0.019 \\
(-0.22)\end{array}$ \\
\hline Age $\times$ Rider Bears Compensation & & $\begin{array}{l}-0.025 \\
(-0.22)\end{array}$ \\
\hline Age $\times$ Reduce Rider's Credit Score & & $\begin{array}{c}0.085 \\
(-0.74)\end{array}$ \\
\hline Age $\times$ ASC & & $\begin{array}{l}-0.674^{* * *} \\
(-3.52)\end{array}$ \\
\hline $\begin{array}{c}\text { Use Frequency } \times 99 \% \text { Arrive } \\
\text { On-Time }\end{array}$ & & $\begin{array}{l}0.059 \\
(-1.63)\end{array}$ \\
\hline Use Frequency $\times 1 \%$ Delay & & $\begin{array}{l}0.026 \\
(-0.7)\end{array}$ \\
\hline $\begin{array}{c}\text { Use Frequency } \times \text { Progressive } \\
\text { Amount }\end{array}$ & & $\begin{array}{c}0.019 \\
(-0.73) \\
\end{array}$ \\
\hline Use Frequency $\times$ Vouchers & & $\begin{array}{l}0.062 * * \\
(-2.36)\end{array}$ \\
\hline $\begin{array}{l}\text { Use Frequency } \times \text { Rider Bears } \\
\text { Compensation }\end{array}$ & & $\begin{array}{l}-0.003 \\
(-0.07)\end{array}$ \\
\hline $\begin{array}{c}\text { Use Frequency } \times \text { Reduce Rider's } \\
\text { Credit Score }\end{array}$ & & $\begin{array}{l}-0.011 \\
(-0.30)\end{array}$ \\
\hline Use Frequency $\times$ ASC & & $\begin{array}{c}0.072 \\
(-1.33)\end{array}$ \\
\hline Observations & 7560 & 7560 \\
\hline Log likelihood & -2172.9518 & -2131.7824 \\
\hline Prob > chi2 & 0.0000 & 0.0000 \\
\hline
\end{tabular}

Note: ${ }^{* *} p<0.01, * * p<0.05, * p<0.1$.

The MNL results show that most variables are significantly correlated at the $p<0.001$ level. This indicates that the variables selected in this study are statistically significant, which means the chosen attributes significantly affect user preferences for delay compensation services. For the attribute "Delay Probability Display", the mean coefficient for "99\% Arrived On-Time" is positive and significant at the $1 \%$ level, indicating that consumers are more inclined to show on-time arrival than showing the delay probability or nothing. The delay possibility display is not significant, indicating that consumers have no clear preference regarding this attribute. For the "Compensation Amount" parameter, the option "Progressive Amount" is significant at the 1\% level, which suggests that consumers prefer the dynamic compensation scheme and that this method increases the utility for the consumers. In terms of compensation methods, the coefficient for the option "Voucher" is negative and significant, indicating that the consumers prefer a cash compensation scheme. For the penalty method, the option "Rider Bears Compensation" has a negative coefficient and is significant at the $5 \%$ level, which means that consumers are against this approach. The consumers have no clear preference for lowering the rider's ratings, which is not directly linked to income or performance. ASC is significant at the $1 \%$ level, and the 
negative coefficient indicates that consumers prefer the given design plan compared to the original state. The results suggest that when the platform wants to promote delay compensation services, displaying the probability of on-time arrival, increasing compensation amount as delay time increases, and paying cash compensation can significantly increase the consumers' utility. Therefore, the results verified Hypothesis 1.

\subsection{Interaction Effect Model Estimation}

Aside from product attributes, the personal characteristics of consumers can also have an impact on the choice of plans [59]. In this study, we examined the interaction between user demographics and the various service attributes. The analysis shows that in the interaction between gender and attributes, women have a negative preference for "99\% Arrive On-Time", while men prefer having the on-time arrival possibility display. Education level has a positive interaction significant at the 5\% level with "Progressive Amount", while education level and "Rider Bears Compensation" have a negative interaction significant at the $10 \%$ level. This means that people with higher education levels prefer "Progressive Amount" and oppose the scheme where the riders would bear the cost. Age has a negative interaction that is significant at the 5\% level, with "99\% Arrive On-Time", indicating that younger users prefer the on-time arrival possibility display. The interaction between use frequency and compensation methods indicates that the more frequently consumers use intra-city delivery, the more they prefer getting vouchers as compensation. Therefore, the results verified Hypothesis 2 .

\subsection{Marginal Willingness to Pay}

The WTP estimation results are summarized in Table 5. The results suggest that consumers have a positive preference for the "99\% Arrive On-Time" display and a progressive compensation scheme. Consumers are willing to pay about 0.49 and 0.40 yuan more for these attributes, exceeding the average market price of 0.30 yuan. Compared with cash compensation, respondents had a negative preference for vouchers, giving a lower WTP of 0.87 yuan. Similarly, the option "Riders Bear Compensation" was found to attenuate consumer utility, with a lower WTP of 0.20 yuan. If platforms adopt attributes with positive consumer preference, people would be willing to pay more for the service, while attributes with negative consumer preferences would require platforms to subsidize some costs for people to accept.

Table 5. Estimation of willingness to pay.

\begin{tabular}{|c|c|c|c|}
\hline Attributes & Marginal Willingness to Pay & Average (Yuan) & Confidence Interval $[5 \%, 95 \%]$ \\
\hline Delay Possibility Display & 99\% Arrive On-Time & 0.49 & {$[0.24,0.74]$} \\
\hline (Benchmark: None) & $1 \%$ Delay & 0.13 & {$[-0.06,0.33]$} \\
\hline $\begin{array}{l}\text { Compensation Amount } \\
\text { (Benchmark: Fixed Amount) }\end{array}$ & Progressive Amount & 0.40 & {$[0.23,0.56]$} \\
\hline $\begin{array}{l}\text { Compensation Method } \\
\text { (Benchmark: Cash) }\end{array}$ & Vouchers & -0.87 & {$[-1.14,-0.61]$} \\
\hline Penalty Method for Riders & Rider Bears Compensation & -0.20 & {$[-0.20,-0.40]$} \\
\hline (Benchmark: None) & Reduce Rider's Credit Score & -0.06 & {$[-0.25,0.12]$} \\
\hline
\end{tabular}

The results show that consumers have various preferences for attributes in the compensation service. Platforms should set up plans that adopt attributes with positive consumer preference in order to enhance their utility and increase the users' willingness to pay.

\section{Discussion}

This paper expands the ideas of research on information reliability, usability, convenience [36], service factors [37], food factor, price factor, and service factor [28], and efficiency [38] in intra-city delivery. The service innovation of intra-city delivery focuses 
on the attribute of delayed compensation service. This study quantitatively analyzed consumer perception on delay compensation services in intra-city delivery using a $\mathrm{CE}$, and many significant main effects and interaction effects are obtained. This proves that $\mathrm{CE}$ is suitable to analyze consumers' preferences for delay compensation service for intracity delivery [11]. At the same time, this is the first study of different attributes of delay compensation service through CE.

Most variables were found to be significantly correlated, which means that these variables are significant determinants of consumer preference and user experience. This indicates that these significant variables all constitute the combinations of various service attributes that were analyzed, namely "Delay Possibility Display", "Compensation Amount", "Compensation Method", "Penalty Method for Riders", and "One-Time Order Price". The experience value of consumers in intra-city delivery service $[16,18]$ is also an extension of the research on service solutions in intra-city delivery research $[19,20]$.

There is no research on the optimization of logistics compensation service in the past [25]. In particular, the role of the main attribute of the deferred service is unclear [28]. In this paper, the respondents were found to prefer having the on-time arrival possibility display and a progressive compensation valuation scheme. In contrast, the respondents opposed using vouchers as the compensation method and requiring the riders to bear the compensation costs. The ASC was significant at the $1 \%$ level, and the negative coefficient indicates that the respondents prefer the provided design to the status quo. These detailed findings confirm previous research that deferred compensation services are a type of active compensation that creates more positive emotions and higher engagement [33]. Although this study did not measure user engagement and positive emotions, a higher pay premium seems to positively imply a higher perceived value for consumers [41].

The interactions between service attributes and respondents' demographics were also explored. Men and younger respondents were found to prefer more the on-time arrival possibility display. Respondents with higher education levels prefer progressive compensation amount and oppose the penalty scheme where the riders would bear compensation. In addition, the more frequent the consumers use intra-city delivery, the more they prefer vouchers for compensation. This interactive analysis of demographic characteristics and attributes reveals two important implications. On the one hand, it reflects the different sensitivities and preferences of different consumers to the attributes of delayed compensation services [32], and on the other hand, it also explains the underlying reasons why $40 \%$ to $60 \%$ of users are dissatisfied with the compensation services [34]. The potential reason for this may be that some attributes that consumers care about are not presented in the compensation scheme. For example, users with high education background are more likely to be dissatisfied with the scheme that penalizes riders. At the same time, we should also be clear that the delay compensation scheme as a way to improve the customer experience [6] needs to take into account the different characteristics of consumers; otherwise, it will be counterproductive.

We also analyzed the influence of different attribute preferences on consumers' marginal willingness to pay. Consumers have a positive preference for "99\% Arrive On-Time" and dynamic compensation amount. The results suggest that the respondents were willing to pay 0.49 and 0.40 yuan more for these attributes, respectively. These values are $63 \%$ and $33 \%$ higher than the average market price for the compensation service valued at 0.3 yuan. These two attribute levels are statistically significant. The respondents had a negative WTP for voucher compensation and "Rider Bears Compensation" attribute levels. This means that these two attribute levels would discount the consumers' value of the whole delay compensation service. If platforms adopt vouchers as the compensation system, an additional cost of about 0.30 yuan would be required to achieve the same effect as having cash reimbursement. This additional cost is higher than the current average price for the compensation service and would therefore not be an efficient and economical option for the platforms. The WTP exploration of compensation service verifies the paradox of service recovery [31]; that is, if some compensation is given for service failure, consumers 
will often have a better service experience. This higher service experience is reflected in consumers' willingness to pay more of their budget for compensation services. Therefore, the significance of compensation services is not only to reduce the negative impact caused by service failures [2] in order to maintain consumer loyalty and trust, but also to improve consumers' positive evaluation of services, thus increasing their payment premium [40].

\subsection{Theoretical Contribution}

This study has two important theoretical contributions. The first theoretical contribution is that this paper is the first study of different attributes of delay compensation service through CE. To be specific, we expand the research perspectives of logistics services, especially extending the optimization of service experience to the micro level of consumer perception. Previous research studies on consumers' perception of logistics services mostly focus on service characteristics [28,37], consumers' perception of services (e.g., consumers' perceived control) [60], consumers' motivations for logistics services (e.g., time and cost savings) [61], or societal pressures (e.g., subjective norm) [52]. However, this paper focuses on a more micro level-the perception difference of specific attributes of service solutions. We not only obtain the influence of different attributes on consumers' willingness to subscribe to compensation services and WTP but also analyze the interaction between different attributes and consumer characteristics. This is a study of intra-city distribution service innovation, which extends the traditional perspective of service innovation to the micro domain of consumer perception and obtains macro service innovation ideas through the micro attribute analysis, so as to improve the loyalty and value perception of consumers in the platform. This also provides a research idea about consumer perception for researchers of subsequent delivery services.

The second contribution is that we study the delay compensation scheme in intra-city distribution by using the standard CE method, which is less used in the light logistics in the past. To be specific, the CE method provides a new tool for subsequent scholars to study logistics service optimization, and this paper can be an important reference for the application of this method. In previous studies on consumer perception in articles on logistics distribution, most of them used the structural equation model to analyze the formation of consumer perception [22], or secondary data were used to obtain consumers' purchase information of distribution services, and quantitative methods were used to analyze the correlation between factors [28,36,37]. Meanwhile, CE was rarely used as a research method to explore the specific values of consumers' purchase intention and willingness to pay in the area of logistics distribution [11,53]. Therefore, in previous studies, it is not possible to observe what causes consumers' dissatisfaction with distribution services and the loss of orders in a detailed and microscopic way. The experimental method represented by $\mathrm{CE}$ can better observe the reasons behind consumers' purchase factors [62] Therefore, in the follow-up research, multiple micro and meso methods can be combined to study the topic of distribution service innovation. This paper is an example of micro research on distribution service innovation.

\subsection{Practical Implication}

The results and analyses show that consumers have different preferences for the attributes of delay compensation services in intra-city delivery. Consumer preference affects the willingness to pay and has significant long-term effects on the delivery service providers. Platforms can modify and improve their delay compensation service plans based on the results. The following are some specific management recommendations:

First, the logistics service platform can design a reasonable delay compensation scheme according to the conclusion of this paper. To be specific, in order to effectively promote delay compensation services as an additional insurance measure, intra-city distribution platforms should modify and develop corresponding plans that adapt service attributes that consumers prefer and are willing to spend on. Platforms that have not yet launched delay compensation services (e.g., UU Paotui, Shansong) may want to consider adopting an 
arrive on-time display, progressive compensation amount, and cash compensation, which have been shown in this study to increase the consumers' utility. For platforms that have already launched delay compensation services (e.g., Fengniao, Xindada, and Meituan), their service plans should be adjusted appropriately. For example, none of these three platforms have utilized the function of displaying the probability of on-time arrival. In this study, we found that respondents were willing to pay $63 \%$ more if provided by this service. The change in some of these attributes of plans require only minimal costs, but they can obtain higher return profits and benefit from positive word-of-mouth marketing.

Second, the logistics service platform can analyze consumer profiles to achieve precision marketing. In exploring the interactions between attributes and consumers' demographics, we found that for different consumers, the attribute preferences vary. This requires that platforms use big data analysis to build consumer profiles to analyze which delay compensation service plans and attributes are more preferred and increase the consumers' willingness to pay. For example, platforms may consider using vouchers to compensate high-frequency users while providing cash refunds to low- and mediumfrequency users. By building consumer demographic databases and analyzing user preferences, platforms can more effectively cater to consumer needs and demands and increase service patronage.

Third, the logistics service platform needs to show more responsibility and tolerance for couriers who cause delayed deliveries. Our results show that penalizing riders by requiring them to bear the costs has a significant negative effect. We found that platforms would need to subsidize 0.20 yuan to cover the negative effect of this scheme. People with higher educational levels are even more averse to this method. This may be because as people get more educated, they become more aware and sympathetic to the challenges of delivery personnel. Delivery service providers are strongly advised that in order to show their corporate responsibility and not cause public backlash, they should keep away from this policy altogether. In this way, people will not be turned off from acquiring the service due to the possibility that the riders would be financially penalized for the delay, and eventually, their recognition and royalty to the platforms could be developed gradually.

\subsection{Limitations and Future Research Directions}

This article analyzed various attributes of delay compensation service in intra-city delivery and explored the consumers' preferred service design. However, there are several limitations of this study that can be explored in future research.

First, there are some factors affecting compensation services that have not been explored and analyzed. So, other attributes of intra-city delivery can be further investigated. For example, default options may affect consumers' choices of products [63]. Platforms can set compensation service as a default option, and if consumers do not need it, they can cancel. An advantage of default options is that it can reduce consumers' negligence and non-selection caused by inertia. Some other contextual attributes can also be explored. For example, order time (i.e., peak time vs. downtime) may affect consumers' preferences for various compensation service attributes. During peak periods, consumers may increase their preference for certain attributes and would be willing to pay more for them.

Second, other characteristics of consumers are worth exploring, and future research can also explore how other consumer characteristics affect attributes preferences. For example, consumers' trust in service platforms [41] and consumers' risk perception [44] may significantly affect consumer preference. Using proper user profiling or questionnaire surveys, platforms would be able to better understand the needs and wants of their consumers or even provide specialized services to a particular segment of their consumer base.

Finally, the causality between attributes and betrothal order needs further verification. In future research, online field experiments can be used to discuss the relationship between attributes and various concepts such as willingness to order, trust, and perceived value. Random grouping can be used to test whether certain service plans can better stimulate 
consumers' willingness to order and increase trust in the platforms. These studies can provide platforms a higher level of competitiveness for their service innovations.

Author Contributions: Data curation, R.P.; Provision of study materials, R.P.; Methodology, R.P.; Supervision, Y.H. and X.X.; Writing-original draft, Y.H.; Writing-review and editing, R.P. and Y.H. All authors have read and agreed to the published version of the manuscript.

Funding: This research was funded by the National Social Science Fund Youth Project of China: (20CGL026).

Institutional Review Board Statement: Not applicable.

Informed Consent Statement: Not applicable.

Data Availability Statement: Not applicable.

Acknowledgments: I would like to thank HouSheng Zhang of Nanjing University. In the process of writing, I was advised by HouSheng Zhang, which made me consider the practicability of the article from multiple perspectives. At the same time, he also encouraged me to complete this paper in an unremitting, rigorous, and serious academic spirit, which is conducive to my lifelong thinking and action.

Conflicts of Interest: The authors declare no conflict of interest.

\section{References}

1. CNNIC. 2018. Available online: http//www.cnnic.net.cn/hlwfzyj/hlwxzbg/hlwtjbg/201803/P020180305409870339136.pdf (accessed on 16 March 2021).

2. Zhang, Z.H.; Xu, B.M. E-commerce Logistics Service Quality Issues Based on Internet Word-of-Mouth Data Mining. China Bus. Mark. 2019, 33, 45-47.

3. Ibaogao. Available online: http://www.chyxx.com/industry/201912/821395.html (accessed on 24 December 2019).

4. Chen, P.; Li, H. Research on Time-Satisfaction- Based O2O Food Delivery Route Optimization. Chin. J. Manag. Sci. 2016, 24, 170-176.

5. Zhao, X.; Zhang, W.J.; He, W.J. Research on the Impact of Logistics Information Technology Adoption on User Ordering Intentions on Online Food Delivery Platforms. Math. Pract. Theory 2020, 50, 46-57.

6. Zhang, X.F. Research on User Experience Optimization of O2O Food Delivery Platform Based on Perceived Waiting Time. Packag. Eng. 2020, 1-8. Available online: http://kns.cnki.net/kcms/detail/50.1094.TB.20200710.1304.016.html (accessed on 16 March 2021).

7. Yang, Z. Research on the Competitive Behavior of Chinese Food Delivery Platform Enterprises-Based on the Perspective of Bilateral Markets. J. Dongbei Univ. Financ. Econ. 2015, 6, 47.

8. Kot, S.; Grondys, K.; Szopa, R. Theory of inventory management based on demand forecasting. Pol. J. Manag. Stud. 2011, 3, 147-155.

9. Li, A.M.; Zhao, D.; Xiong, G.X.; Tan, F.; Wang, X.; Ling, W. Is waiting a torture? Perception of Waiting Time and The Resulting Irrational Decision-making Behavior. Adv. Psychol. Sci. 2014, 22, 1679-1690. [CrossRef]

10. Sun, X.L.; Feng, S.M.; Wu, H.Y. The Impact of Platform Environment and Waiting Behavior on Perception of Waiting Time. J. Harbin Inst. Technol. 2019, 51, 186-190.

11. Ghvanidze, S.; Velikova, N.; Dodd, T.H.; Oldewage-Theron, W. Consumers' environmental and ethical consciousness and the use of the related food products information: The role of perceived consumer effectiveness. Appetite 2016, 107, 311-322. [CrossRef]

12. Cho, M.; Bonn, M.A.; Li, J.J. Differences in perceptions about food delivery apps between single-person and multi-person households. Int. J. Hosp. Manag. 2019, 77, 108-116. [CrossRef]

13. Bernal Jurado, E.; Mozas Moral, A.; Medina Viruel, M.J.; Fernández Uclés, D. Evaluation of corporate websites and their influence on the performance of olive oil companies. Sustainability 2018, 10, 1274. [CrossRef]

14. Goodman, E.; Kuniavsky, M.; Moed, A. Observing the User Experience: A Practitioner's Guide to User Research. IEEE Trans. Prof. Commun. 2013, 56, 260-261. [CrossRef]

15. Liu, Y.L.; Li, H. Design of Interactive Interface Based on Conceptual Metaphor Theory. Packag. Eng. 2012, 33, 17-19.

16. Li, N. Study on the factors influencing the willingness to purchase insurance in the Internet scenario-Taking zing-bao as an example. Beijing Univ. Int. Bus. Econ. 2020, 1, 55.

17. Jiao, Z. Service Mode and Development Trend of the "Last-Mile Delivery" of E-commerce Logistics. In Contemporary Logistics in China; Springer: Berlin, Germany, 2016; pp. 239-261.

18. Chiu, C.M.; Hsu, M.H.; Lai, H.; Chang, C.-M. Re-examining the Influence of Trust on Online Repeat Purchase Intention: The Moderating Role of Habit and Its Antecedents. Decis. Support Syst. 2012, 53, 835-845. [CrossRef]

19. Wang, Y.; Potter, A.; Naim, M.; Beevor, D. A case study exploring drivers and implications of collaborative electronic logistics marketplaces. Ind. Mark. Manag. 2011, 40, 612-623. [CrossRef] 
20. Luo, Y.T.; Liu, G. Research on the Relationship between Logistics Service Innovation and Logistics Demand-Based on The Perspective of Symbiosis Theory. Contemp. Financ. Econ. 2011, 2, 61-68.

21. Zhang, G.M. Research on Innovation Mode of Logistics Service. Econ. Manag. 2006, 18, 57-61.

22. Belanche, D.; Flavián, M.; Pérez-Rueda, A. Mobile apps use and wom in the food delivery sector: The role of planned behavior, perceived security and customer lifestyle compatibility. Sustainability 2020, 12, 4275. [CrossRef]

23. Chapman, R.L.; Soosay, C.; Kandampully, J. Innovation in Logistic Services and The New Business Model: A Conceptual Framework. Int. J. Phys. Distrib. Logist. Manag. 2002, 33, 630-650. [CrossRef]

24. Zhang, X.Q. E-commerce Logistics Service Innovation Based on Big Data. China Bus. Mark. 2018, 32, $15-22$.

25. Zhang, X.H.; Ma, T.S. Research on Value-added Logistics of Online Shopping under the Background of Big Data. Contemp. Econ. Manag. 2015, 37, 29-33.

26. Rao, S.; Goldsby, T.J.; Griffis, S.E.; Iyengar, D. Electronic Logistics Service Quality(e-LSQ): Its Impact on the Customer's Purchase Satisfaction and Retention. J. Bus. Logist. 2011, 32, 167-179. [CrossRef]

27. Zhang, C.B.; Li, D.J.; Wu, B.; Duan, J.H. Research on the Negative Influence Mechanism of Online Shopping Perceived Waiting Time-Order Processing Time vs. Product Delivery Time. Lanzhou Acad. J. 2016, 2, 176-186.

28. Zeng, J.Q.; Wang, F. Research and Empirical Analysis of User Satisfaction of O2O Online Food Delivery. J. Mod. Inf. 2015, 8, 17-21.

29. Kim, H.R. Developing an index of online customer satisfaction. J. Financ. Serv. Mark. 2005, 10, 49-64. [CrossRef]

30. Holloway, B.B.; Beatty, S.E. Service failure in online retailing: A recovery opportunity. J. Serv. Res. 2003, 6, 92-105. [CrossRef]

31. Chebat, J.; Davidow, M.; Codijovi, I. Silent Voices Why Some Dissatisfied Consumers Fail to Complain. J. Serv. Res. 2005, 4 328-342. [CrossRef]

32. Matos, C.A.D.; Henrique, J.L.; Rossi, C.A.V. Service Recovery Paradox: A Meta-analysis. J. Serv. Res. 2007, 10, 60-77. [CrossRef]

33. Zhang, S.L.; Gao, H. The Impact of Service Recovery Methods on Consumer Emotions and Behavior Intentions. Nankai Bus. Rev. 2011, 14, 37-43.

34. Tax, S.S.; Brown, S.W. Recovering and learning from service failure. Sloan Manag. Rev. 1998, 40, 75-88.

35. Pencarelli, T.; Škerháková, V.; Ali Taha, V.; Valentiny, T. Factors determining Italian online shoppers' preference of cash on delivery: Empirical analysis. Pol. J. Manag. Stud. 2018, 18. [CrossRef]

36. Chen, H.T.; Li, T.Q.; Song, N.N. Modeling and Empirical Research on Repeated Purchase Behavior of Online Food Delivery Platform Users. Soft Sci. 2015, 29, 79-82.

37. Gao, H.; Yang, B.W.; Wang, J. Research on Influencing Factors of Repeated Consumption Intention under O2O E-commerce Takeaway Mode. Commer. Res. 2015, 58, 126-132.

38. Riang, R. Research on the Impact of O2O Online Food Delivery User Satisfaction on The Repeated Consumption Intentions. Bus. Econ. 2017, 5, 71-73.

39. He, Z.; Han, G.; Cheng, T.C.E.; Fan, B.; Dong, J. Evolutionary Food Quality and Location Strategies for Restaurants in Competitive Online-to-offine Food Ordering and Delivery Markets: An Agent-based Approach. Int. J. Prod. Econ. 2018, $26,1-12$.

40. Bienstock, C.C.; Royne, M.B.; Sherrell, D.; Stafford, T.F. An Expanded Model of Logistics Service Quality: Incorporating Logistics Information Technology. Int. J. Prod. Econ. 2008, 113, 205-222. [CrossRef]

41. Wout, M.V.; Sanfey, A.G. Friend or Foe: The Effect of Implicit Trustworthiness Judgments in Social Decision-making. Cognition 2008, 108, 796-803. [CrossRef]

42. Shankar, V.; Urban, G.L.; Sultan, F. Online trust: A stakeholder perspective, concepts, implications, and future directions. J. Strateg. Inf. Syst. 2002, 11, 325-344. [CrossRef]

43. Kossecki, P. Who and How Should Build the Trust in Ecommerce? Res. Pol. Internet Shops 2005. [CrossRef]

44. Roghanizad, M.; Neufeld, D.J. Intuition, Risk, and the Formation of Online Trust. Comput. Hum. Behav. 2015, 50, 489-498. [CrossRef]

45. McKnight, D.H.; Choudhury, V.; Kacmar, C. The Impact of Initial Consumer Trust on Intentions to Transact with a Web Site: A Trust Building Model. J. Strateg. Inf. Syst. 2002, 11, 297-323. [CrossRef]

46. Belanche, D.; Casaló, L.V.; Flavián, C.; Pérez-Rueda, A. The role of customers in the gig economy: How perceptions of working conditions and service quality influence the use and recommendation of food delivery services. Serv. Bus. 2021, 15, 1-31. [CrossRef]

47. Yang, X.; Huang, Y.; Cai, X.; Song, Y.; Jiang, H.; Chen, Q.; Chen, Q. Using Imagination to Overcome Fear: How Mental Simulation Nudges Consumers' Purchase Intentions for Upcycled Food. Sustainability 2021, 13, 1130. [CrossRef]

48. Huang, Y.; Li, X.; Li, J. Analogying with Memory or Simulating the Results?-The Matching Effect of Learning Strategy and Regulatory Focus on Consumers' Intelligent Hardware Adoption. Collect. Essays Financ. Econ. 2020, 9, 84-93.

49. Lancaster, K.J. A New Approach to Consumer Theory. J. Polit. Econ. 1996, 74, 132-157. [CrossRef]

50. Chen, M.; Wang, Y.Q.; Yin, S.J.; Hu, W.Y.; Han, F. Chinese Consumer Trust and Preferences for Organic Labels from Different Regions. Br. Food J. 2019, 12, 1521-1535. [CrossRef]

51. Gao, Z.F.; Yu, X.H.; Li, C.G.; McFadden, B.R. The Interaction between Country of Origin and Genetically Modified Orange Juice in Urban China. Food Qual. Prefer. 2019, 71, 475-484. [CrossRef]

52. Louviere, J.J.; Hensher, D.A.; Swait, J.D. Stated choice methods: Analysis and applications. J. Appl. Econ. $2002,17,4$.

53. Blamey, R.K.; Bennett, J.W.; Louviere, J.J.; Morrison, M.D.; Rolfe, J.C. Attribute Causality in Environmental Choice Modelling. Environ. Resour. Econ. 2002, 23, 167-186. [CrossRef] 
54. Tversky, A.; Kahneman, D. The framing of decisions and the psychology of choice. Science 1981, 211, 453-458. [CrossRef]

55. Kessels, R.; Goos, P.; Vandebroek, M. A Comparison of Criteria to Design Efficient Choice Experiments. J. Mark. Res. 2006, 43, 409-419. [CrossRef]

56. Gadema, Z.; Oglethorpe, D. The Use and Usefulness of Carbon Labelling Food: A Policy Perspective from A Survey of UK Supermarket Shoppers. Food Policy 2011, 36, 815-822. [CrossRef]

57. Huang, Y.; Sengupta, J. The influence of disease cues on preference for typical versus atypical products. J. Consum. Res. 2020, 47, 393-411. [CrossRef]

58. Yang, X.; Huang, Y.; Han, M.; Wen, X.; Zheng, Q.; Chen, Q.; Chen, Q. The Differential Effects of Physical Activity Calorie Equivalent Labeling on Consumer Preferences for Healthy and Unhealthy Food Products: Evidence from a Choice Experiment. Int. J. Environ. Res. Public Health 2021, 18, 1860. [CrossRef]

59. Auger, P.; Devinney, T.M. Do What Consumers Say Matter? The Misalignment of Preferences with Unconstrained Ethical Intentions. J. Bus. Ethics 2007, 76, 361-383. [CrossRef]

60. Yang, H.C. Bon Appétit for apps: Young American consumers' acceptance of mobile applications. J. Comput. Inf. Syst. 2013, 53, 85-96. [CrossRef]

61. Yeo, V.C.S.; Goh, S.K.; Rezaei, S. Consumer experiences, attitude and behavioral intention toward online food delivery (OFD) services. J. Retail. Consum. Serv. 2017, 35, 150-162. [CrossRef]

62. Tyrväinen, L.; Mäntymaa, E.; Juutinen, A.; Kurttila, M.; Ovaskainen, V. Private landowners' preferences for trading forest landscape and recreational values: A choice experiment application in Kuusamo, Finland. Land Use Policy 2020, 104478. [CrossRef]

63. Van Kleef, E.; Seijdell, K.; Vingerhoeds, M.H.; de Wijk, R.A.; van Trijp, H.C. The Effect of A Default-based Nudge on the Choice of Whole Wheat Bread. Appetite 2018, 121, 179-185. [CrossRef] [PubMed] 